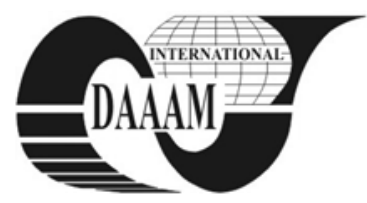

Annals of DAAAM for 2011 \& Proceedings of the 22nd International DAAAM Symposium, Volume 22, No. 1, ISSN 1726-9679 ISBN 978-3-901509-83-4, Editor B. Katalinic, Published by DAAAM International, Vienna, Austria, EU, 2011 Make Harmony between Technology and Nature, and Your Mind will Fly Free as a Bird

\title{
A NEW EFFICIENT IMPLEMENTATION OF REDUNDANCY IN ELECTRONIC SYSTEMS
}

\author{
PANAIT, C[ornel]; DRAGOMIRESCU, O[vidiu] \& CARUNTU, G[eorge]
}

\begin{abstract}
The paper presents a universal solution, simple and efficient to implement redundancy in electronic systems that process external signals. It is presented the structural schematic diagram of a redundant system in which notification of any defect and correct interpretation of the break signal is carried by comparing the output signal from the base unit to the signal provided by a standard or control block, which in principle is identical to the base.

Key words: redundant amplifier, basic unit block, control block, backup block, mean time between failures
\end{abstract}

\section{INTRODUCTION}

The paper presents the problem of efficiently implementing amplifiers for which the reservation is made at any kind of failure at the base block.

In literature there are known low power redundant amplifiers, at which the reservation is made only when a major failure appears. In our case the reservation is made even when small distortions occur, or at a small change in frequency characteristics.

The solution for identifying defects is based on the use of a control block, whose output signal is compared with the signal from the base block. If there are any differences, the reservation is made.

This solution increases twice the proper average of good functioning if no renewals are made and with 50-100 times if renewals are made.

The solution can be applied to any electronic system.

\section{A UNIVERSAL SOLUTION, SIMPLE AND EFFICIENT TO IMPLEMENT REDUNDANCY IN ELECTRONIC SYSTEMS THAT PROCESS EXTERNAL SIGNALS}

A redundant system (Cătuneanu, 1989, Geffroy, 1989, Drujinin 1968) consists of a basic block-BB, one or more backup blocks -BR and a switch to pass to backup-CR, which is intended to refer to the basic block failure and order entry of the reserves into system. A good C.R. switch must comply with the following conditions:

- notify any malfunction in the basic block and ensure switch to the reserve at the appearance of any malfunction (for example, in the case of linear amplifier, it must not notify only the defects that cause signal loss or strong attenuation of the output signal, but other possible defects such as defects which change the frequency characteristic, increasing gain or distortion, causing the system to oscillate );

- not to interpret the signal breaks or low-level signals, as defects of the basic block and, thus, not to command the switch to backup in these cases;

Satisfying these requirements generally seems very difficult. In reality, notification of any defect and interpretation of the signal breaks in the case of electronic systems (linear, nonlinear or digital)

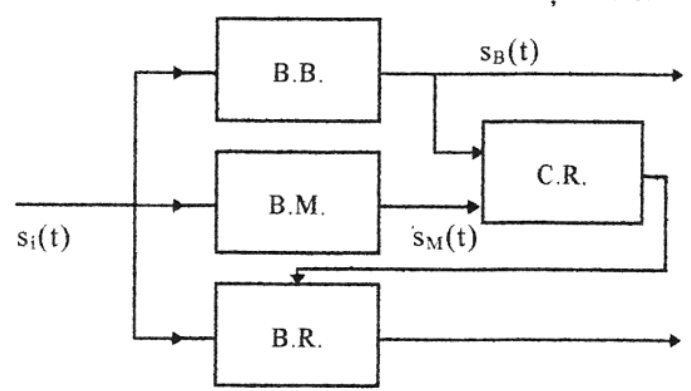

Fig. 1. The block diagram of a redundant system (B.B. - basic unit/block; B.M. - control block; B.R. - backup block; C.R.switching to backup circuit)

which process external signals, can be done simply and effectively done by using the principle of comparison, which means constantly comparing the output signal of the basic block $s_{B}(t)$ with the signal of a control block or reference block $s_{M}(t)$, which in principle is the same as the basic block.

The block diagram of a redundancy system built on this idea is shown in figure 1. BM control block provides at its output a signal $s_{M}(t)$ identical to the output signal of the basic unit in good working order.

The C.R. circuit makes the operation of subtraction between signals $S_{B}(t)$ and $s_{M}(t)$ and when the result is not zero and exceeds a certain required level, it commands the switch to the backup block. In the case of broadband linear systems, control block may be missing, as it can make a direct comparison between input signal $s_{i}(t)$ and output signal $S_{B}(t)$, if it is adequately mitigated by a passive network. However, for reasons of noise or frequency characteristic, it may require the use of a control block. In case of selective linear systems (selective amplifiers) or the nonlinear systems and digital systems, the control block may not be missing because in these cases a direct comparison between the signals $s_{i}(t)$ and $s_{B}(t)$ is not possible, because these signals have different waveforms and frequency spectrums.

It is generally preferable but not mandatory that the control unit be more reliable than the basic block and the backup block.

Thus, for example, if the basic block and the backup block are power amplifiers, control unit can be a simple voltage amplifier which should have just the same characteristic frequency as the basic unit and so, by default, will have a better reliability. If $\mathrm{BB}$ and $\mathrm{BR}$ are voltage amplifiers, or generally low power blocks, then BM will be identical and will have the same reliability as well. CR circuit is basically a simple structure. 
For analogue systems (Manolescu, 1983, Gray, 1996) it is reduced to a simple differential circuit $s_{B}(t)-s_{M}(t)$ that can be achieved with operational amplifier, or a simple resistive adder, if control unit is designed to provide an output signal $-s_{B}(t)=s_{M}(t)$.

For digital systems it is reduced to an exclusive-OR circuit or more generally to a $\mathrm{N}$-bit comparator, where $\mathrm{N}$ is the number of outputs that need to be compared. It should be noted that for digital systems, where BB and BM have independent clocks, synchronism differences between signals $s_{B}(t)$ and $s_{M}(t)$ may occur, which could be misinterpreted as a defect in the BB. To avoid this it is necessary that both BB and BM use the same clock. The proposed solution for achieving redundancy has the following advantages:

- it can be applied to any electronic system for processing external signals;

- it automatically satisfies the three conditions mentioned at the beginning of this paragraph, and allows notification of defects which allows even very small modification of the output signal;

- in some cases control block may lack;

- in principle the number of spare blocks may be increased and may make a ring reservation.

Equivalent circuit in terms of reliability consists of a series group BB-BM which is parallel with BR. Intrinsic reliability function of the reserved system is (Karaulova,2008, Cătuneanu 1989):

$$
R_{r}=R_{B R}+R_{B B} R_{B M}-R_{B \mathbf{B}} R_{B R} R_{B M}
$$

where $R_{B \mathrm{~B}}, R_{B M}, R_{B R}$ are reliability functions corresponding to the three blocks.

If the blocks are identical, $R_{B \mathbf{B}}=R_{B R}=R_{B M}=R$ it results:

$$
R_{r}=R+R^{2}-R^{3}
$$

and the efficiency of reservation is: $\gamma=\frac{1}{1-R^{2}}>1$, for any given time $\mathrm{t}$.

If $R(t)=e^{-\lambda t}$, for mean time between failures (MTBF) without restore it results : $\left.m_{r}\right|_{\text {loaded }}=1,16 m$; $\left.m_{r}\right|_{\text {unloaded }}=1,5 m$, where $m=1 / \lambda$.

If $R_{B M}>R_{B B}=R_{B R}=e^{-\lambda t}$, it is obtained: $R_{r} \cong 2 R-R^{2}$

$\left.m_{r}\right|_{\text {loaded }}=1,5 m ;\left.m_{r}\right|_{\text {unloaded }}=2 m$.

If the system is restoring, and if we assume for its blocks constant restore constant intensity $\mu$, then the average time between failures of its operation, and charged back will be:

$$
m_{r}^{*}=1,5 m\left(\frac{2}{3}+\frac{\mu}{3 \lambda}\right)
$$

meaning $m_{r}=6 m$ if $\mu / \lambda=10$ or $m_{r}=51 m$ if $\mu / \lambda=100$. Clearly, if the reserve will be unloaded the reliability gain will be even greater.

\section{REDUNDANT AMPLIFIERS}

A fair solution to achieve a redundancy amplifier after the original scheme proposed above is given in figure 2 .

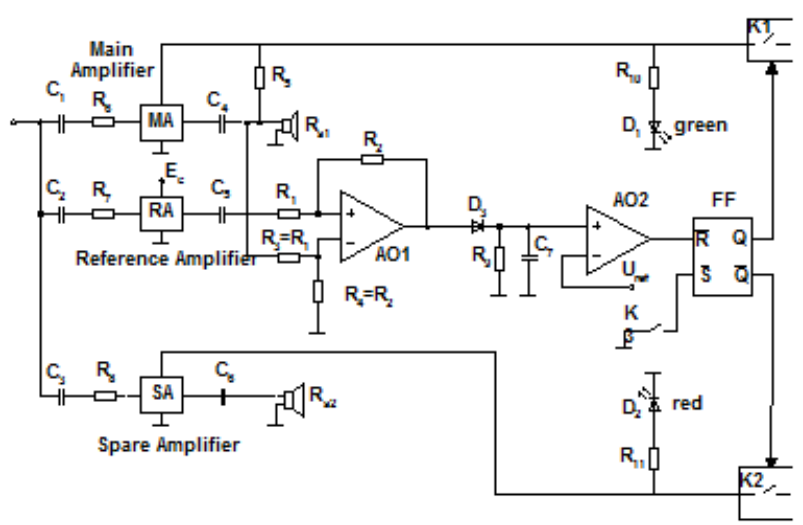

Fig. 2. Redundant amplifier

The solution has the following advantages:

reserve is unloaded and therefore blocking efficiency is maximum;

- by replacing an RS flip-flop with a T flip-flop we can get an ring reservation;

- by replacing the flip-flop with a shift register, we can increase the number of reservations and ensure a reservation in the ring.

Based on this scheme, several laboratory models were conducted for studying redundancy amplifiers.

\section{CONCLUSIONS}

The redundant amplifiers, set up according to the original solution previously presented, have the following essential advantages:

- they notice and perform the switch to back-up amplifier for any malfunctioning type within the main amplifier (the amplifier which insures the functioning of the system);

- can notice even the slightest deviation in the functioning of the main amplifier;

- can be used in all practical cases, irrespective of the signal structure - with or without spaces, with or without

- level variations-;

- when a malfunctioning occurs within the main amplifier, it is automatically removed from the system and there is an automatic switch to the back-up amplifier, which makes the external intervention of a human operator unnecessary;

- the circuit which acknowledges the malfunctioning of the main amplifier and performs the switch to the back-up amplifier is a simple and very reliable circuit, made of uncomplicated components, which usually have a high reliability;

- the back-up amplifier (amplifiers) remains unloaded until it enters the system (without loading tension), which gives the redundant system a high reliability;

- they can be easily adapted so as to realize a ring back-up and / or to increase the number of back-ups.

\section{REFERENCES}

Cătuneanu V., Mihalache A. "Reliability fundamental", ELSEVIER Amsterdam ,Oxford, Tokio1989

Drujinin G.V., "Siguranţa în funcţionare a sistemelor", Editura Tehnică, Bucuresti 1968

Geffroy J.C., "Surete de functionnement des systems informatiques", 1989

Gray P., Mayer R., „Circuite integrale liniare. Analiză şi Proiectare", Editura Tehnică, Bucureşti, 1996

Karaulova T., Preis I., Pribytkova M., "Process Analysis and Reliability Evaluation", Annals of DAAAM for 2008,pp. 0659-0660, Published by DAAAM International Vienna

Manolescu A., "Circuite integrate liniare”, Editura Didactică şi Pedagogică, Bucureşti 1983 